\title{
Desempenho e composição dos filés de jundiás (Rhamdia quelen) submetidos a diferentes dietas na fase de recria
}

\author{
[Performance and fillet composition of jundiá (Rhamdia quelen) submitted to different diets in the rearing] \\ R. Lazzari ${ }^{1}$, J. Radünz Neto ${ }^{1,4}$, F.A. Pedron ${ }^{1}$, C.A. Veiverberg ${ }^{1}$, G.T. Bergamin ${ }^{1}$, \\ R.L. Lima', T. Emanuelli ${ }^{3}$, C. Steffens ${ }^{3}$, \\ ${ }^{1}$ Departamento de Zootecnia (Lab. Piscicultura) - UFSM \\ Av. Roraima, 1000 \\ 97105-900 - Santa Maria, RS \\ ${ }^{2}$ Universidade Federal de Santa Catarina - Florianópolis, SC \\ ${ }^{3}$ Departamento de Tecnologia e Ciência dos Alimentos - UFSM - Santa Maria, RS \\ ${ }^{4}$ Bolsista do $\mathrm{CNPq}$
}

\begin{abstract}
RESUMO
Avaliaram-se o crescimento e a composição dos filés de juvenis de jundiá após 90 dias de alimentação com dietas contendo diferentes fontes protéicas. Foram utilizados 540 peixes, peso inicial $=15,0 \pm 0,62 \mathrm{~g}$; comprimento inicial $=11,98 \pm 0,35 \mathrm{~cm}$, distribuídos ao acaso em 18 tanques (30 peixes $/$ tanque) com sistema de recirculação de água. Foram testadas seis dietas: 1 - farinha de carne e ossos + levedura (CL), 2 - farelo de soja + levedura (SL), 3 - farelo de soja (S), 4 - farinha de carne e ossos + farelo de soja (CS), 5 - farinha de peixe + levedura (PL) e 6 - farinha de peixe + farelo de soja (PS). Avaliaram-se: peso, comprimento total, taxa de crescimento específico, fator de condição, sobrevivência, conversão alimentar aparente, taxa de eficiência protéica e consumo diário. Também foram analisadas as composições do filé - umidade, proteína, lipídios, cinzas -, as taxas de deposição de proteína e gordura, além dos rendimentos de filé e carcaça. Maiores pesos, 111,5 e $108,6 \mathrm{~g}$, comprimento total, 22,6 e $21,6 \mathrm{~cm}$, e taxa de crescimento específico, 2,1 e 2,2\%/dia, foram observados nos peixes alimentados com as dietas CS e PS. Os peixes alimentados com CS e PS também apresentaram maior deposição de proteína, 69,8 e 71,5mg/dia, e lipídios, 77,2 e 78,3mg/dia. A sobrevivência foi menor na dieta PS, 92,9\%. Os maiores rendimentos de carcaça foram observados nos peixes alimentados com PS e PL, 82,9 e $82,7 \%$, e o menor rendimento de filé ocorreu na dieta CL, $34,1 \%$.
\end{abstract}

Palavras-chave: peixe, jundiá, fonte protéica, composição do filé, crescimento

\begin{abstract}
The growth and fillet composition of jundiá juveniles after 90 days being fed with diets containing different protein sources were evaluated. Five hundred and forty fish (initial weight: $15.00 \pm 0.62 \mathrm{~g}$; initial length: $11.98 \pm 0.35 \mathrm{~cm}$ ) were randomly distributed in 18 tanks (30 fish/tank), in a water re-use system. Six diets were tested: 1- meat and bone meal + yeast (CL), 2- soybean meal + yeast (SL), 3- soybean meal (S), 4- meat and bone meal + soybean meal (CS), 5- fish meal + yeast (PL,) and 6-fish meal + soybean meal (PS). The following parameters were evaluated: weight, total length, specific growth rate, condition factor, survival, feed conversion ratio, protein efficiency ratio, and daily consumption. Fillet composition (moisture, protein, lipid, and ash), protein and lipid depositions ratios, carcass and fillet yields were also determined. The highest values of weight (111.5 and 108.6g), total length (22.6 and 21.6cm), and specific growth rate (2.1 and $2.2 \% /$ day), were observed in fish fed CS and PS diets. Fish fed CS and PS diets also showed the highest protein (69.8 and 71.5mg/day), and lipid depositions (77.2 and 78.3mg/day). Survival was smaller in fish fed diet PS (92.86\%). The highest values of carcass yield were observed in fish fed PL and PS diets (82.9 and 82.7\%), and the lower fillet yield was observed in CL diet (34.1\%).
\end{abstract}

Keywords: fish, jundiá, protein source, fillet composition, growth

Recebido em 15 de maio de 2007

Aceito em 18 de março de 2008

*Autor para correspondência (corresponding author)

E-mail: jradunzneto@yahoo.com.br 


\section{INTRODUÇÃO}

O jundiá ( $R$. quelen) é um bagre nativo da América Latina, habita lagos e rios, sendo muito apreciado para consumo nos países deste continente (Salhi et al., 2004). A aceitação de diferentes alimentos, boa adaptação à criação em cativeiro, rápido crescimento e excelente sabor da carne fazem desta espécie uma das mais promissoras da piscicultura brasileira (Coldebella e Radünz Neto, 2002; Barcellos et al., 2004).

A alimentação representa o maior custo da produção de peixes e determina, além do crescimento, a qualidade do produto final (El Sayed, 1999). Dessa forma, os ingredientes utilizados nas rações devem possuir boa composição, homogeneidade e disponibilidade constante no mercado (Lovell, 1991). Alimentos de origem animal, principalmente farinha de peixe, são freqüentemente utilizados, entretanto apresentam maior custo (Webster et al., 1992). O valor biológico da proteína, associado à boa quantidade de aminoácidos essenciais, justifica o uso destas fontes em rações para peixes (Webster et al., 1995). Com o avanço da produção de peixes no mundo, a demanda por estes ingredientes aumentará, sendo que a produção não atenderá esta necessidade (Wurts, 2000). Portanto, é importante utilizar fontes de proteína de baixo custo e que proporcionem bom crescimento dos peixes (Kaushik et al., 2004).

A utilização de fontes de origem vegetal em rações para peixes vem sendo amplamente estudada (Tacon, 1993). Bons resultados foram obtidos com os bagres norte-americanos (Ictalurus punctatus e I. furcatus), quando alimentados com quantidades significativas de farelo de soja (Webster et al., 1992). Alevinos de jundiá alimentados com farelo de soja associado à levedura de cana apresentam bom crescimento (Coldebella e Radünz Neto, 2002).

A composição dos filés dos peixes afeta a qualidade e a aceitabilidade, sendo o lipídio o componente mais variável (Geri et al., 1995). Para o jundiá, estudos mostram que a deposição lipídica está associada ao nível lipídico e à relação proteína-energia da dieta (Melo et al., 2002; Meyer e Fracalossi, 2004). Dietas não específicas para cada espécie podem ocasionar excesso de deposição lipídica. Isso eleva o custo de produção, diminui a eficiência alimentar e a qualidade da carne (Reis et al., 1989). Alevinos de channel catfish apresentam menor deposição lipídica quando alimentados com farelo de soja em detrimento a fontes de origem animal (Mohsen e Lovell, 1990).

Os estudos realizados sobre a nutrição do jundiá relatam trabalhos na fase larval e de alevinagem (Luchini, 1990; Coldebella e Radünz Neto, 2002; Melo et al., 2002; Meyer e Fracalossi, 2004; Salhi et al., 2004). Este trabalho foi realizado para avaliar o desempenho e a composição de filés de jundiás alimentados com diferentes fontes de proteína.

\section{MATERIAL E MÉTODOS}

O experimento foi realizado durante 90 dias, entre janeiro e abril de 2004. Foram utilizados 540 peixes, peso inicial $=15,00 \pm 0,62 \mathrm{~g}$, obtidos por meio de reprodução induzida. As instalações experimentais foram compostas por um sistema de recirculação de água com 18 unidades experimentais (2801), temperatura controlada, filtragem biológica e sistema de aeração tipo Venturi (Radünz Neto et al., 1987). Cada unidade experimental foi constituída por uma caixa contendo 30 peixes (densidade de estocagem inicial: $1,6 \mathrm{~g} / \mathrm{l}$; vazão inicial: 2,51/min). Antes do experimento, os animais foram colocados em um tanque de concreto e submetidos a tratamento profilático com sal comum (4g/l) (Miron et al., 2003).

Os parâmetros físico-químicos da água foram aferidos diariamente: temperatura $\left({ }^{\circ} \mathrm{C}\right)$, amômia total (ppm), nitrito (ppm), alcalinidade $\left(\mathrm{mgCaCO}_{3} / \mathrm{l}\right), \mathrm{pH}$ e oxigênio dissolvido (ppm). Para medição da temperatura, foi usado um termômetro; para oxigênio, um oxímetro digital ${ }^{1}$; para $\mathrm{pH}$, um pHmetro digital e, para os demais parâmetros, um kit colorimétrico ${ }^{2}$. Os parâmetros de qualidade de água do sistema de criação foram: temperatura $\left(26,85 \pm 1,02^{\circ} \mathrm{C}\right)$, amônia total $(0,50 \pm 0,22 \mathrm{ppm}), \quad$ nitrito $(0,06 \pm 0,01 \mathrm{ppm})$, alcalinidade $\quad\left(48,96 \pm 13,40 \mathrm{mgCaCO}_{3} / 1\right), \quad \mathrm{pH}$ $(7,30 \pm 0,26)$ e oxigênio dissolvido $(5,53 \pm 0,62 \mathrm{ppm})$. Esses valores estão dentro da faixa considerada adequada para a criação da espécie (Gomes et al., 2000).

${ }^{1}$ Digimed - São Paulo, Brasil.

${ }^{2}$ Alfakit - Florianópolis, Brasil. 
Foram formuladas seis dietas-teste, utilizando a combinação de fontes protéicas (farinha de carne e ossos bovina, farelo de soja, farinha de peixe e levedura de cana) conforme Tab. 1. Após a mistura, cada alimento foi umedecido, peletizado em máquina de moer carne e colocado em estufa de circulação de ar forçado para secagem $\left(50-55^{\circ} \mathrm{C}\right)$. A alimentação foi oferecida duas vezes ao dia $(9$ e $17 \mathrm{~h})$, até a saciedade aparente.

Ao final do período experimental, 90 dias de alimentação, todos os peixes foram capturados, pesados e medidos para avaliação do desempenho.
Foram avaliados os seguintes parâmetros: peso final $(\mathrm{g})$; comprimento total $(\mathrm{cm})$; sobrevivência total; taxa de crescimento específico, segundo a fórmula: $\mathrm{TCE}=\left\{\left[\log _{\mathrm{n}}\right.\right.$ (peso final $)-\log _{\mathrm{n}}$ (peso inicial $\left.\left.)\right] / 90\right\} \mathrm{x}$ 100 ; fator de condição: $\mathrm{FC}=[($ peso $) /($ comprimento total $\left.\left.{ }^{3}\right) \times 100\right]$; conversão alimentar aparente: $\mathrm{CAA}=$ alimento oferecido $(\mathrm{g}) /$ ganho em peso $(\mathrm{g})$; taxa de eficiência protéica: $\mathrm{TEP}=$ ganho em peso (g)/consumo de proteína $(\mathrm{g})$; consumo diário: $\mathrm{CD}=\{($ consumo total $(\mathrm{g}) /[$ (peso final + peso inicial)/2] / 90) x 100\}.

Tabela 1. Formulação e composição das dietas experimentais (\%) para jundiás na fase de recria

\begin{tabular}{|c|c|c|c|c|c|c|}
\hline \multirow{2}{*}{ Ingrediente } & \multicolumn{6}{|c|}{ Dieta } \\
\hline & $\mathrm{CL}$ & SL & $\mathrm{S}$ & $\mathrm{CS}$ & $\mathrm{PL}$ & PS \\
\hline Levedura de cana & 28,0 & 33,2 & - & - & 25,9 & - \\
\hline Farinha de carne e ossos & 38,5 & - & - & 30,0 & - & - \\
\hline Farinha de peixe & - & - & - & - & 30,0 & 22,4 \\
\hline Farelo de soja & - & 33,2 & 68,5 & 32,0 & - & 30,0 \\
\hline Milho & 15,0 & 13,4 & 12,4 & 16,9 & 20,0 & 19,5 \\
\hline Farelo de trigo & 8,0 & 10,0 & 10,0 & 8,0 & 15,0 & 18,0 \\
\hline Óleo de canola & 7,4 & 7,0 & 6,0 & 10,0 & 6,0 & 7,0 \\
\hline Sal comum & 1,0 & 1,0 & 1,0 & 1,0 & 1,0 & 1,0 \\
\hline Fosfato bicálcico & 1,0 & 1,0 & 1,0 & 1,0 & 1,0 & 1,0 \\
\hline Mistura vitamínica e mineral ${ }^{1}$ & 1,0 & 1,0 & 1,0 & 1,0 & 1,0 & 1,0 \\
\hline Antioxidante $^{2}$ & 0,02 & 0,02 & 0,02 & 0,02 & 0,02 & 0,02 \\
\hline Nutriente & \multicolumn{6}{|c|}{ Composição (\%) } \\
\hline Proteína bruta $^{3}$ & 34,6 & 32,1 & 33,0 & 34,4 & 32,9 & 31,9 \\
\hline Matéria mineral $^{3}$ & 13,2 & 5,2 & 6,2 & 12,9 & 9,9 & 10,7 \\
\hline Lipídios $^{3}$ & 12,7 & 8,0 & 7,2 & 16,4 & 9,8 & 11,4 \\
\hline Fibra bruta ${ }^{3}$ & 1,8 & 3,09 & 4,2 & 3,6 & 1,8 & 3,6 \\
\hline Umidade $^{3}$ & 6,9 & 7,9 & 8,9 & 5,5 & 6,5 & 8,0 \\
\hline Cálcio $^{3}$ & 3,4 & 1,3 & 1,5 & 3,0 & 2,1 & 2,1 \\
\hline Fósforo $^{3}$ & 2,0 & 0,7 & 0,8 & 1,8 & 1,5 & 1,5 \\
\hline Energia digestível $^{4}(\mathrm{~kJ} / \mathrm{g})$ & 14,3 & 13,2 & 12,9 & 15,1 & 13,6 & 13,5 \\
\hline Arginina $^{5}$ & 1,7 & 1,8 & 2,5 & 2,1 & 1,7 & 2,1 \\
\hline Fenilalanina $^{5}$ & 1,0 & 1,4 & 1,8 & 1,2 & 1,2 & 1,4 \\
\hline Histidina $^{5}$ & 0,5 & 0,7 & 0,9 & 0,6 & 0,9 & 1,0 \\
\hline Isoleucina $^{5}$ & 1,0 & 1,4 & 1,6 & 1,0 & 1,3 & 1,3 \\
\hline Lisina $^{5}$ & 2,0 & 2,0 & 2,1 & 1,9 & 2,1 & 2,0 \\
\hline Leucina $^{5}$ & 1,8 & 2,2 & 2,6 & 1,9 & 2,2 & 2,3 \\
\hline Metionina + cistina $^{5}$ & 0,8 & 0,8 & 1,0 & 0,8 & 0,9 & 0,9 \\
\hline Treonina $^{5}$ & 1,1 & 1,4 & 1,4 & 1,0 & 1,4 & 1,2 \\
\hline Triptofano $^{5}$ & 0,1 & 0,2 & 0,4 & 0,2 & 0,2 & 0,4 \\
\hline Valina $^{5}$ & 1,3 & 1,6 & 1,7 & 1,3 & 1,5 & 1,5 \\
\hline
\end{tabular}

CL: farinha de carne e ossos + levedura; SL: farelo de soja + levedura; S: farelo de soja; CS: farinha de carne e ossos + farelo de soja; PL: farinha de peixe + levedura; PS: farinha de peixe + farelo de soja.

${ }^{1}$ Conteúdo p/kg produto: vit.A: 600000UI; vit.B1: 1400mg; vit.B2: 3375mg; vit.B6: 4830mg; vit.B12: 5000mcg; vit.C: 25000mg; vit.D3: 530000UI; vit.E: $22500 \mathrm{mg}$; vit.K3: 5000mg; zinco: 40000mg. ácido fólico: 400mg; ácido nicotínico: 14000mg; cobalto: $1500 \mathrm{mg}$; ácido pantotênico: $8000 \mathrm{mg}$; cobre: $15000 \mathrm{mg}$; colina: $1500 \mathrm{mg}$; ferro: $50000 \mathrm{mg}$; iodo: $700 \mathrm{mg}$; manganês: $23000 \mathrm{mg}$; selênio: $250 \mathrm{mg}$.

${ }^{2} 32 \%$ etoxiquina; $18 \%$ propil-galato; $50 \%$ inerte.

${ }^{3}$ Valores analisados.

${ }^{4} \mathrm{ED}=[(23.6 \mathrm{~kJ} / \mathrm{g} \times$ \%Proteína $\times 0.9)+(39.8 \mathrm{~kJ} / \mathrm{g} \times$ \%Lipídios x 0.85) + (17.2 kJ/g x \%Cho x 0.5)]/100 (Jobling, 1995).

${ }^{5}$ Valores calculados (Ajinomoto Biolatina Ind. e Com. Ltda.). 
Após as medições, foram capturados três peixes por tanque (nove por tratamento), que foram pesados, anestesiados (trifenóxi-etanol-0,03\%) e abatidos para a determinação dos rendimentos de cortes. A carcaça foi considerada como o peixe eviscerado, com cabeça e brânquias. Os dois filés de cada peixe foram coletados. Da porção restante, após a retirada do filé, também foi retirado o chamado músculo abdominal.

Para as análises de composição dos filés, nove peixes por dieta foram utilizados. A proteína do filé foi determinada pelo método de Kjeldahl utilizando 6,25 como fator de conversão. A umidade e as cinzas foram determinadas por meio da metodologia descrita nas Normas Analíticas do Instituto Adolfo Lutz (Instituto..., 1985). A determinação dos lipídios está de acordo com a metodologia descrita em Lanara (Laboratório..., 1981), após hidrólise ácida. A partir da composição inicial e final e dos rendimentos inicial e final dos filés, foram calculadas taxas de deposição de proteína e gordura (Camargo et al., 1999).
O delineamento experimental utilizado foi $\mathrm{o}$ inteiramente ao acaso, com seis tratamentos e três repetições. Os dados foram submetidos a testes de normalidade e após análise de variância. As médias foram comparadas pelo teste Duncan $(\mathrm{P}<0,05)$, utilizando o pacote estatístico SAS (User's ..., 1997). Os valores foram expressos como média \pm erro-padrão da média.

\section{RESULTADOS}

Ao final dos 90 dias de alimentação (Tab. 2), observou-se maior peso nos peixes alimentados com farelo de soja combinado com farinha de peixe ou farinha de carne e ossos, dietas CS e PS. Os jundiás alimentados somente com a dieta $\mathrm{S}$ apresentaram menor crescimento $(30,8 \mathrm{~g})$. A taxa de crescimento específico (TCE) dos peixes alimentados com a dieta PS $(2,2 \% /$ dia) não diferiu da taxa dos da dieta CS (2,1\%/dia), entretanto foi maior que a dos demais tratamentos. A TCE dos peixes alimentados com levedura, dietas CL, SL e PL, foi maior que a dos submetidos somente ao farelo de soja (dieta $\mathrm{S}$ ).

Tabela 2. Desempenho e rendimento de cortes de juvenis de jundiá de acordo com a dieta (média \pm erropadrão)

\begin{tabular}{lcccccc}
\hline \multirow{2}{*}{ Variável } & \multicolumn{7}{c}{ Dieta } \\
\cline { 2 - 7 } & $\mathrm{CL}$ & $\mathrm{SL}$ & $\mathrm{S}$ & $\mathrm{CS}$ & $\mathrm{PL}$ & $\mathrm{PS}$ \\
\hline CT (cm) & $21,3 \pm 0,2 \mathrm{~b}$ & $19,7 \pm 0,4 \mathrm{c}$ & $16,1 \pm 0,1 \mathrm{~d}$ & $22,6 \pm 0,7 \mathrm{a}$ & $20,6 \pm 0,2 \mathrm{bc}$ & $21,6 \pm 0,2 \mathrm{ab}$ \\
P (g) & $92,2 \pm 0,3 \mathrm{~b}$ & $69,1 \pm 3,7 \mathrm{c}$ & $30,8 \pm 0,6 \mathrm{~d}$ & $111,5 \pm 4,6 \mathrm{a}$ & $89,5 \pm 1,5 \mathrm{~b}$ & $108,6 \pm 1,7 \mathrm{a}$ \\
TCE (\%/dia) & $1,9 \pm 0,1 \mathrm{c}$ & $1,7 \pm 0,1 \mathrm{~d}$ & $0,8 \pm 0,2 \mathrm{e}$ & $2,1 \pm 0,1 \mathrm{ab}$ & $2,0 \pm 0,1 \mathrm{bc}$ & $2,2 \pm 0,1 \mathrm{a}$ \\
FC & $0,9 \pm 0,3 \mathrm{bc}$ & $0,8 \pm 0,2 \mathrm{c}$ & $0,7 \pm 0,1 \mathrm{~d}$ & $0,9 \pm 0,2 \mathrm{bc}$ & $1,0 \pm 0,1 \mathrm{ab}$ & $1,1 \pm 0,1 \mathrm{a}$ \\
S (\%) & $100,0 \mathrm{a}$ & $98,4 \pm 1,5 \mathrm{a}$ & $98,4 \pm 1,5 \mathrm{a}$ & $100,0 \mathrm{a}$ & $100,0 \mathrm{a}$ & $92,8 \pm 2,3 \mathrm{~b}$ \\
CAA & $1,5 \pm 0,1 \mathrm{c}$ & $2,0 \pm 0,1 \mathrm{~b}$ & $4,5 \pm 0,1 \mathrm{a}$ & $1,4 \pm 0,3 \mathrm{de}$ & $1,6 \pm 0,1 \mathrm{~cd}$ & $1,3 \pm 0,1 \mathrm{e}$ \\
TEP & $1,1 \pm 0,3 \mathrm{c}$ & $0,9 \pm 0,1 \mathrm{~d}$ & $0,7 \pm 0,2 \mathrm{e}$ & $1,3 \pm 0,1 \mathrm{~b}$ & $1,2 \pm 0,1 \mathrm{c}$ & $1,5 \pm 0,1 \mathrm{a}$ \\
CD (\%PV) & $4,0 \pm 0,101 \mathrm{~b}$ & $4,8 \pm 0,1 \mathrm{a}$ & $3,1 \pm 0,1 \mathrm{~d}$ & $3,7 \pm 0,1 \mathrm{bc}$ & $4,1 \pm 0,1 \mathrm{~b}$ & $3,4 \pm 0,1 \mathrm{c}$ \\
RC (\%) & $77,8 \pm 0,3 \mathrm{~d}$ & $81,9 \pm 0,5 \mathrm{ab}$ & $80,1 \pm 0,6 \mathrm{c}$ & $81,0 \pm 0,1 \mathrm{bc}$ & $82,7 \pm 0,4 \mathrm{a}$ & $82,9 \pm 0,3 \mathrm{a}$ \\
RF (\%) & $34,1 \pm 1,4 \mathrm{~b}$ & $40,1 \pm 1,0 \mathrm{a}$ & $39,1 \pm 1,1 \mathrm{a}$ & $38,7 \pm 1,8 \mathrm{ab}$ & $37,8 \pm 1,4 \mathrm{ab}$ & $40,6 \pm 0,3 \mathrm{a}$ \\
MA(\%) & $10,6 \pm 2,6 \mathrm{a}$ & $12,7 \pm 0,8 \mathrm{a}$ & $10,6 \pm 0,6 \mathrm{a}$ & $12,3 \pm 0.5 \mathrm{a}$ & $13,2 \pm 1,1 \mathrm{a}$ & $11,6 \pm 0,5 \mathrm{a}$ \\
\hline
\end{tabular}

Médias com letras distintas na linha diferem entre si pelo teste Duncan $(\mathrm{P}<0,05)$.

CL: farinha de carne e ossos + levedura; SL: farelo de soja + levedura; S: farelo de soja; CS: farinha de carne e ossos + farelo de soja; PL: farinha de peixe + levedura; PS: farinha de peixe + farelo de soja.

CT: comprimento total do peixe (cabeça-cauda); P: peso final obtido ao final do experimento; TCE: taxa de crescimento específico $=\left\{\left[\log _{n}\right.\right.$ (peso final) - $\log _{n}($ peso inicial $\left.\left.)\right] / 90\right\} x$ x 100; FC:fator de condição= $[($ peso $) /$ (comprimento total $\left.\left.{ }^{3}\right) \times 100\right]$; S: sobrevivência; CAA: conversão alimentar aparente: consumo de alimento (g)/ganho em peso (g); TEP: taxa de eficiência proteica=ganho em peso (g) / consumo de proteína (g); CD: consumo diário $=\{($ consumo total $(\mathrm{g}) /[($ peso final + peso inicial $) / 2] / 90) \times 100\} ; \mathrm{RC}$ : rendimento de carcaça $=[($ peso peixe eviscerado X 100)/peso peixe inteiro]; RF: rendimento de filé=[(peso dos filés X 100)/peso peixe inteiro]; MA: músculo abdominal=[(peso dos músculos abdominais X 100)/peso peixe inteiro]. 
Os peixes alimentados com a dieta CS apresentaram maior comprimento total $(22,6 \mathrm{~cm})$. Valores semelhantes foram observados nos peixes alimentados com farinha de peixe, dietas PL e PS e CL. O fator de condição dos juvenis alimentados somente com farelo de soja foi de 0,7 , inferior aos demais tratamentos. Não foram observadas diferenças no $\mathrm{FC}$ dos peixes alimentados com farinha de peixe, dietas PL e PS. Observou-se menor sobrevivência $(92,8 \%)$ nos jundiás do tratamento $\mathrm{PS}$, e não ocorreu mortalidade nas dietas CL, CS e PL.

Os melhores valores de conversão alimentar foram observados nos tratamentos que apresentaram maior peso final, CS e PS. Os peixes da dieta $\mathrm{S}$ apresentaram pior conversão alimentar aparente $(4,5: 1)$. Os alimentados com a dieta PS tiveram maior taxa de eficiência protéica, mais que o dobro da dieta S. Maior consumo foi observado nos juvenis da dieta SL $(4,8 \%)$, enquanto os da dieta $\mathrm{S}$ apresentaram o menor $(3,1 \%)$.

Os rendimentos de carcaça e filé foram menores nos peixes alimentados com farinha de carne e ossos e levedura, 77,9 e 34,1\%, respectivamente. Nos demais tratamentos, os valores de RC foram mais altos que $80 \%$. Não se verificou diferença nos valores de rendimento de músculo abdominal.

Maior quantidade de lipídios no filé foi observada nos peixes alimentados com a dieta CS (7,2\%). A quantidade de matéria mineral dos filés dos peixes da dieta CL foi menor que a da PS (Tab. 3). As maiores taxas de deposição de proteína e lipídios foram verificadas nas dietas CS, farinha de carne e ossos e farelo de soja, e PS, farinha de peixe e farelo de soja.

Tabela 3. Composição centesimal dos filés de jundiás após 90 dias de alimentação (média \pm erro-padrão), de acordo com a dieta

\begin{tabular}{lcccccc}
\hline & \multicolumn{7}{c}{ Dieta } \\
\cline { 2 - 7 } & $\mathrm{CL}$ & $\mathrm{SL}$ & $\mathrm{S}$ & $\mathrm{CS}$ & $\mathrm{PL}$ & PS \\
\hline Umidade & $75,8 \pm 0,5 \mathrm{~b}$ & $75,3 \pm 0,4 \mathrm{bc}$ & $77,9 \pm 0,4 \mathrm{a}$ & $74,2 \pm 0,7 \mathrm{c}$ & $76,5 \pm 0,3 \mathrm{ab}$ & $76,6 \pm 0,5 \mathrm{ab}$ \\
Proteína & $16,6 \pm 0,1 \mathrm{bc}$ & $17,9 \pm 0,7 \mathrm{a}$ & $17,6 \pm 0,1 \mathrm{ab}$ & $17,4 \pm 0,2 \mathrm{abc}$ & $17,5 \pm 0,2 \mathrm{abc}$ & $17,8 \pm 0,1 \mathrm{a}$ \\
Lipídios & $4,7 \pm 0,2 \mathrm{bc}$ & $4,5 \pm 0,5 \mathrm{~cd}$ & $3,2 \pm 0,5 \mathrm{~d}$ & $7,2 \pm 0,3 \mathrm{a}$ & $4,0 \pm 0,5 \mathrm{~cd}$ & $4,3 \pm 0,4 \mathrm{bcd}$ \\
Cinzas & $1,1 \pm 0,1 \mathrm{~b}$ & $1,2 \pm 0,2 \mathrm{ab}$ & $1,2 \pm 0,4 \mathrm{ab}$ & $1,2 \pm 0,1 \mathrm{ab}$ & $1,2 \pm 0,4 \mathrm{ab}$ & $1,3 \pm 0,3 \mathrm{a}$ \\
\multicolumn{7}{c}{ Taxas de deposição } \\
TPDF & $47,1 \mathrm{~b} / \mathrm{dia})$ & & $71,5 \mathrm{a}$ \\
TGDF & $54,3 \mathrm{~b}$ & $45,0 \mathrm{~b}$ & $13,1 \mathrm{c}$ & $69,8 \mathrm{a}$ & $51,2 \mathrm{~b}$ & $78,3 \mathrm{a}$ \\
\hline
\end{tabular}

Composição inicial: umidade: 76,6\%; proteína: 16,4\%; lipídios: 5,6\%; cinzas: 1,0\%. Valores expressos na matéria natural.

Médias com letras distintas na linha diferem entre si pelo teste Duncan $(\mathrm{P}<0,05)$.

CL: farinha de carne e ossos + levedura; SL: farelo de soja + levedura; S: farelo de soja; CS: farinha de carne e ossos + farelo de soja; PL: farinha de peixe + levedura; PS: farinha de peixe + farelo de soja.

TPDF: total de proteína depositada no filé; TGDF: total de gordura depositada no filé.

\section{DISCUSSÃO}

Os dados são importantes na avaliação de fontes de proteína para o jundiá, assunto ainda pouco estudado. Foi observado que a combinação das fontes de origem animal, farinha de carne e ossos e de peixe, com farelo de soja proporcionou bom crescimento aos peixes. A farinha de peixe é o ingrediente referência nas rações, principalmente pelo equilíbrio e boa fonte de aminoácidos essenciais (Masumoto et al., 1996). Apesar do hábito alimentar onívoro, o jundiá é considerado um peixe exigente em relação à qualidade da proteína (Meyer e Fracalossi, 2005).
O crescimento observado nos peixes alimentados com dietas contendo levedura, CL, SL e PL, foi abaixo do esperado. Coldebella e Radünz Neto (2002) mostraram que a combinação entre a levedura e o farelo de soja proporciona excelente taxa de crescimento $\left(4,9 \% \mathrm{dia}^{-1}\right)$ e peso para alevinos de jundiá. Uma das prováveis causas da discrepância desses resultados com os obtidos neste estudo está relacionada com a qualidade das matérias-primas, farinha de carne e ossos, utilizadas, que podem apresentar variação de composição e problemas oxidativos (Tacon, 1993; El Sayed, 1999). 
O perfil de aminoácidos das dietas foi similar (Tab. 1), e não se pode atribuir o baixo crescimento dos peixes alimentados com as dietas sem inclusão de fontes de origem animal, $\mathrm{SL}$ e $\mathrm{S}$, a esse fator. Estudos com outras espécies mostraram que a mistura de ingredientes proporciona melhor balanço de aminoácidos essenciais, dispensando a utilização de fontes de origem animal (El-Saidy e Gaber, 2003; Kaushik et al., 2004). Além disso, o tempo de alimentação pode ter influenciado, pois modificações na síntese de proteína e atividade enzimática podem manifestar-se após longos períodos de alimentação (Lopez et al., 1999; Krogdahl et al., 1994).

Outro aspecto importante a considerar neste estudo é a influência da relação proteína-energia da dieta. As dietas CS e PS, que resultaram em maior crescimento, possuíam maior teor de lipídios em relação à quantidade de proteína. $\mathrm{O}$ jundiá apresenta a capacidade de economizar proteína quando se eleva a concentração de lipídios do alimento, sendo este o responsável pelo fornecimento de energia e a proteína direcionada para o crescimento (Meyer e Fracalossi, 2004).

O crescimento reduzido observado nos peixes alimentados somente com farelo de soja provavelmente ocorreu devido aos fatores antinutricionais que este ingrediente possui, quando utilizado em maiores níveis (Kaushik et al., 1995). Estes fatores adversos provocam inibição enzimática, baixo consumo e decréscimo na síntese protéica, claramente observada nos parâmetros produtivos dos jundiás deste estudo. Outros fatores que podem contribuir são a suplementação de fósforo, presente nos ingredientes vegetais na forma de fitato, que é pouco disponível, bem como o desbalanceamento de alguns aminoácidos essenciais (Hasan et al., 1997).

O alto nível de inclusão de farelo de soja na dieta $\mathrm{S}(68,5 \%)$ foi evidenciado pelo menor peso dos peixes. A tolerância pela utilização desse ingrediente depende da espécie e também do período de alimentação (Lopez et al., 1999). Alevinos de blue catfish (Ictalurus furcatus) alimentados com dietas contendo 69\% de farelo de soja não apresentaram redução na utilização de proteína e consumo de alimento (Webster et al., 1992). Entretanto, o peso final foi inferior quando comparado a dietas com inclusão de farinha de peixe.

Juvenis de channel catfish (peso inicial 18g), alimentados com dietas contendo $40 \%$ de farinha de peixe e $6 \%$ de farelo de soja por nove semanas, apresentaram conversão alimentar de 1,25:1 (Mohsen e Lovell, 1990), similar ao obtido com a dieta PS do presente estudo $(1,28: 1)$. Esse valor é excelente tratando-se de um peixe onívoro de água quente, neste caso o jundiá. Jundiás criados em tanques de terra alimentados com dieta comercial (32\% apresentaram CAA de 1,4:1 (Fracalossi et al., 2004) similar à do presente estudo.

Os valores de rendimento de carcaça observados são similares aos obtidos por Melo et al. (2002) com juvenis de jundiá alimentados com diferentes fontes lipídicas, aproximadamente $80 \%$. Trutas alimentadas somente com ingredientes de origem vegetal apresentam menor rendimento de carcaça em detrimento de peixes alimentados com farinha de peixe (Francesco et al., 2004). Isso pode estar relacionado à composição e deposição de tecidos.

A avaliação da composição química da carne do peixe é fundamental, pois influencia na qualidade e na vida de prateleira do produto final (filé). Existem poucos estudos sobre a qualidade dos filés de jundiá, o que dificulta a avaliação dos resultados obtidos neste trabalho em comparação com outras espécies. De maneira geral, foi observada maior deposição de gordura em relação à proteína em todos os tratamentos. Os peixes alimentados com a dieta CS apresentaram quantidade similar de lipídios que os da dieta PS. Clement e Lovell (1994) observaram $17,3 \%$ de proteína e $7,4 \%$ de lipídios em filés de catfish, valores similares aos dos jundiás alimentados com a dieta CS (Tab. 3). Os resultados obtidos no presente estudo poderão servir para futuros trabalhos com o jundiá, para comparação de resultados e avaliação da qualidade da carne.

Da mesma forma, os resultados deste experimento mostraram que a combinação do farelo de soja com as fontes de origem animal testadas, farinha de peixe ou de carne e ossos, proporciona bom crescimento para o jundiá. Por outro lado, o farelo de soja utilizado como fonte 
protéica principal proporciona pior crescimento, sendo necessários futuros trabalhos para determinar níveis adequados de inclusão em dietas para o jundiá ( $R$. quelen).

\section{CONCLUSÕES}

Conclui-se que a mistura de farelo de soja com farinha de carne e ossos ou farinha de peixe proporciona bom desempenho para jundiás na fase de recria.

\section{REFERÊNCIAS BIBLIOGRÁFICAS}

BARCELLOS, L.J.G.; KREUTZ, L.C.; QUEVEDO, R.M. et al. Nursery rearing of jundiá, Rhamdia quelen (Quoy \& Gaimard) in cages: cage type, stocking density and stress response to confinement. Aquaculture, v.232, p.383-394, 2004.

CAMARGO, A.C.S.; VIDAL JÚNIOR, M.V.; DONZELE, J.L. et al. Níveis de energia metabolizável para Tambaqui (Colossoma macropomum) dos 30 aos 180 gramas de peso vivo. 1.Composição das carcaças. Rev. Bras. Zootec., v.27, p.409-415, 1999.

CLEMENT, S.; LOVELL, R.T. Comparison of processing yield and nutrient composition of cultured Nile tilapia (Oreochromis niloticus) and channel catfish (Ictalurus punctatus). Aquaculture, v.119, p.299-310, 1994.

COLDEBELLA, I.J.; RADÜNZ NETO, J. Farelo de soja na alimentação de alevinos de jundiá (Rhamdia quelen). Cienc. Rural, v.32, p.499503, 2002.

EL-SAIDY, D.M.S.D.; GABER M.M.A. Replacement of fish meal with a mixture of different plant protein sources in juvenile Nile tilapia, Oreochromis niloticus (L.) diets. Aquac. Res., v.34, p.1119-1127, 2003.

EL-SAYED, A.F.M. Alternative dietary protein sources for farmed tilapia Oreochromis niloticus spp. Aquac. Res., v.179, p.149-168, 1999.

FRACALOSSI, D.M.; MEYER, G.; SANTAMARIA, F.M. et al. Desempenho do jundiá, Rhamdia quelen, e do dourado, Salminus brasiliensis, em viveiros de terra na região sul do Brasil. Acta Scient., v.26, p.345-352, 2004.

FRANCESCO, M.; PARISI, G.; MÉDALE, F. et al. Effect of long-term feeding with a plant protein mixture based diet on growth and body/fillet quality traits of large rainbow trout (Oncorhynchus mykiss). Aquaculture, v.236, p.413-429, 2004.

GERI, G.; POLI, B.M.; GUALTIERI, M. et al. Body traits and chemical composition of muscle in the common carp (Cyprinus carpio L.) as influenced by age and rearing environment. Aquaculture, v.129, p.329-333, 1995.

GOMES, L.C.; GOLOMBIESKI, J.I.; CHIPPARI-GOMES, A.R. et al. Biologia do jundiá Rhamdia quelen (Teleostei, Pimelodidae). Cien. Rural, v.30, p.179-185, 2000.

HASAN, M.R.; MACINTOSH, D.J.; JAUNCEY, K. Evaluation of some plant ingredients as dietary protein sources for common carp (Cyprinus carpio L.) fry. Aquaculture, v.151, p.55-70, 1997.

JOBLING, M. Environmental biology of fishes. New York: Chapman \& Hall, 1995. 455p.

KAUSHIK, S.J.; COVÈS, D.; DUTTO, G. et al. Almost total replacement of fish meal by plant protein sources in the diet of a marine teleost, the European seabass, Dicentrarchus labrax. Aquaculture, v.230, p.391-404, 2004.

KAUSHIK, S.J.; CRAVEDI, J.P.; LALLES, J.P. et al. Partial or total replacement of fish meal by soybean protein on growth protein utilization, potential estrogenic or antigenic effects, cholesterolemia and flesh quality in rainbow trout, Oncorhynchus mykiss. Aquaculture, v.133, p.257-274, 1995.

KROGDAHL, A.; LEA, T.B.; OLLI, J.J. Soybean proteinase inhibitors affect intestinal trypsin activities and amino acid digestibilities in rainbow trout (Oncorhynchus mykiss). Comp. Bioch. Phys., v.107, p.215-219, 1994.

LÓPEZ, M.F.J.; MARTÍNEZ DÍAZ, I.; DÍAZ LÓPEZ, M. et al. Inhibition of digestive proteases by vegetable meal in three fish species; seabream (Sparus aurata), tilapia (Oreochromis niloticus) and African sole (Solea senegalensis). Comp. Bioch. Phys., v.122B, p.327-332, 1999.

LOVELL, R.T. Nutrition of aquaculture species. J. Anim. Sci., v.69, p.4193-4200, 1991.

LUCHINI, L. Manual para el cultivo del bagre sudamericano (Rhamdia sapo). Santiago: ONU, 1990. 60p. (RLAC/90/16 - PES-20 - 04/90). 
MASUMOTO, T.; RUCHIMAT, T.; ITO, Y. et al. Amino acid availability values for several protein sources for yellowtail (Seriola quinqueradiata). Aquaculture, v.146, p.109-119, 1996.

MELO, J.F.B.; RADÜNZ NETO, J.; SILVA, J.H.S. et al. Desenvolvimento e composição corporal de alevinos de jundiá (Rhamdia quelen) alimentados com dietas contendo diferentes fontes de lipídios. Cienc. Rural, v.32, p.323-327, 2002 .

MÉTODOS analíticos oficiais para controle de produtos de origem animal e seus ingredientes. II - Métodos físicos e químicos. Brasília: LANARA, p.2-7, 1981.

MEYER, G.; FRACALOSSI, D.M. Protein requirement of jundia fingerlings, Rhamdia quelen, at two dietary energy concentrations. Aquaculture, v.240, p.331-343, 2004.

MEYER, G.; FRACALOSSI, D.M. Estimation of jundia (Rhamdia quelen) dietary amino acid requirements based on muscle amino acid composition. Sci. Agr., v.62, p.401-405, 2005.

MIRON, D.S.M.; SILVA, L.V.F.; GOLOMBIESKI, J.I. et al. Efficacy of different salt $(\mathrm{NaCl})$ concentrations in the treatment of Ichthyophitirius multifiliis - infected Silver Catfish, Rhamdia quelen, fingerlings. J. Appl. Aquac., v.14, p.155-161, 2003.

MOHSEN, A.A.; LOVELL, R.T. Partial substitution soybean meal with animal protein sources in diets for channel catfish. Aquaculture, v.90, p.303-311, 1990.

NORMAS analíticas. Métodos químicos e físicos para análise de alimentos. São Paulo: Instituto Adolfo Lutz, 1985. v.1, p.21-27.
RADÜNZ NETO, J.; KOHLER, C.C.; LEWIS, W.M. Water re-use system of fingerling fishes in Brasil with emphasis on South American catfishes (Rhamdia quelen and R. sapo). Trop. Agric., v.64, p.2-6, 1987.

REIS, L.M.; REUTEBUCH, E.M.; LOVELL, R.T. Protein-to-energy ratios in production diets and growth, feed conversion and body composition of channel catfish, Ictalurus punctatus. Aquaculture, v.77, p.21-27, 1989.

SALHI, M.; BESSONART, M.; CHEDIAK, G. et al. Growth, feed utilization and body composition of black catfish, Rhamdia quelen, fry fed diets containing different protein and energy levels. Aquaculture, v.231, p.435-444, 2004.

TACON, A.G.J. Feed ingredients for warm water fish: fish meal and other processed feedstuffs. Rome: FAO, 1993. 64p. (FAO Fisheries Circular, 856).

USER'S guide. Version 6.08. 4.ed. Cary, NC: SAS Institute, 1997. 846p.

WEBSTER, C.D.; TIDWELL, J.H.; TIU, L.S. Use of soybean meal as partial or total substitute of fish meal in diets for blue catfish (Ictalurus furcatus). Aquat. Liv. Res., v.8, p.379-384, 1995.

WEBSTER, C.D.; YANCEY, D.H.; TIDWELL, J.H. Effect of partially or totally replacing fish meal with soybean meal on growth of blue catfish (Ictalurus furcatus). Aquaculture, v.103, p.141-152, 1992.

WURTS, W.A. Sustainable Aquaculture in twenty-first century. Rev. Fish. Sci., v.8, p.141150, 2000. 